\title{
Delayed Cytoreductive Nephrectomy Following Three Years of Targeted Therapy for Metastatic Renal Cell Carcinoma
}

\author{
Ariel Schulman ${ }^{\mathrm{a}} \quad$ Mathew Fakhoury $^{\mathrm{a}} \quad$ Jean P. Wuilleumier ${ }^{\mathrm{b}} \quad$ Kevin Becker $^{\mathrm{c}}$ \\ Bernadine Donahue $^{d} \quad$ Ruoqing Huang ${ }^{e}$ James Butler ${ }^{d}$ Howard Goodman ${ }^{f}$ \\ Ervin Teper $^{9} \quad$ David Silver ${ }^{9}$ \\ a Duke University Medical Center, Durham, N.C.; ${ }^{b}$ Department of General Surgery; ' Division of Hematology/Oncology, Department \\ of Medicine; ${ }^{\mathrm{d}}$ Division of Radiation Oncology; ${ }^{\mathrm{e}}$ Division of Pathology; ${ }^{\mathrm{f}}$ Division of Orthopedic Oncology, Department of Orthope- \\ dics Surgery, and 'Division of Urologic Oncology, Maimonides Medical Center, Brooklyn, N.Y., USA
}

\section{Key Words}

Renal cell carcinoma - Laparoscopic nephrectomy •

Cytoreductive nephrectomy • Targeted therapy •

Metastatic renal cell carcinoma

\begin{abstract}
We present a 55-year-old male, with good performance status who was diagnosed with a case of metastatic renal cell carcinoma following a pathologic femur fracture. Despite good performance status, multifocal metastases and poor-prognostic features portended a grim prognosis with predicted overall survival of less than nine months. On initial presentation, he was excluded from cytoreductive nephrectomy based on brain metastasis and interleukin-2 was not pursued as the primary tumor was to be left in situ. The patient was reconsidered for cytoreductive nephrectomy after sustained response to fifth line targeted therapies with shrinkage of tumor burden. The post-operative course was uneventful and the patient was discharged home on postoperative day one. Temsirolimus was resumed one week after surgery and the patient reported returning to his normal activities at the two week follow-up visit. We highlight important clinical features of metastatic renal cell carcinoma,
\end{abstract}

\section{KARGER}

Fax +4161306 1234

E-Mail karger@karger.ch

www.karger.com
(C) 2015 S. Karger AG, Basel

1015-9770/15/0093-0202\$38.00/0

Accessible online at:

www.karger.com/cur the surgical considerations for cytoreductive nephrectomy and the detailed multidisciplinary care the patient received throughout this case report.

Copyright $\odot 2015$ S. Karger AG, Basel

\section{Case Report}

A 55-year-old healthy male sustained a right femur fracture following a fall in September 2011 managed with intramedullary rod placement (fig. 1A). Several weeks of poor healing prompted further imaging that showed a soft tissue mass in the femoral shaft and biopsy was consistent with metastatic clear cell carcinoma, most likely renal origin. Subsequent computed tomography (CT) imaging of the chest, abdomen and pelvis revealed an $11 \times 10$ $\mathrm{cm}$ left upper pole renal mass with $3.8 \mathrm{~cm}$ para-aortic adenopathy (fig. 2A) and a $9 \mathrm{~mm}$ left lower lobe lung nodule. Magnetic resonance imaging of the brain showed a $7 \mathrm{~mm}$ enhancing mass in the superior, left parietal lobe with vasogenic edema suggestive of metastatic disease (fig. 1B). The urologic oncology service was consulted for further management.

On initial encounter, the patient denied constitutional symptoms, hematuria or neurologic deficits. Past medical history was significant for hypertension and a remote left ankle fracture. Fam- 


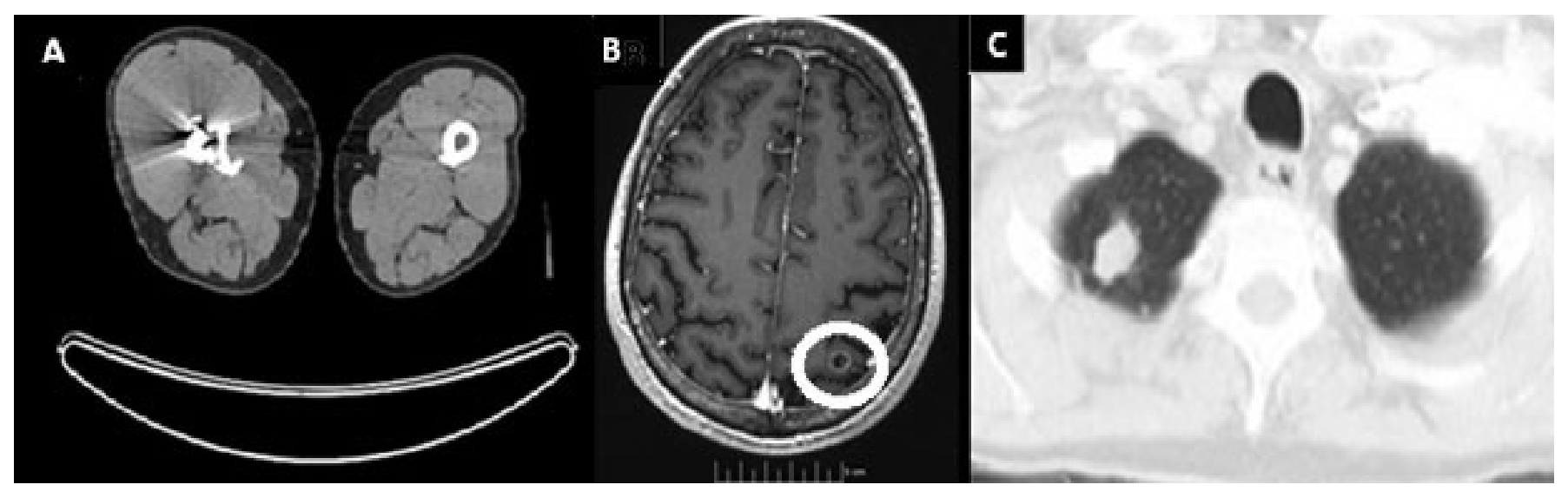

Fig. 1. A Pathologic fracture of right femur, status post fixation. B $7 \mathrm{~mm}$ enhancing mass in the superior, left parietal lobe with vasogenic edema. C New $3 \mathrm{~cm}$ right lung nodule, signifying disease progression.

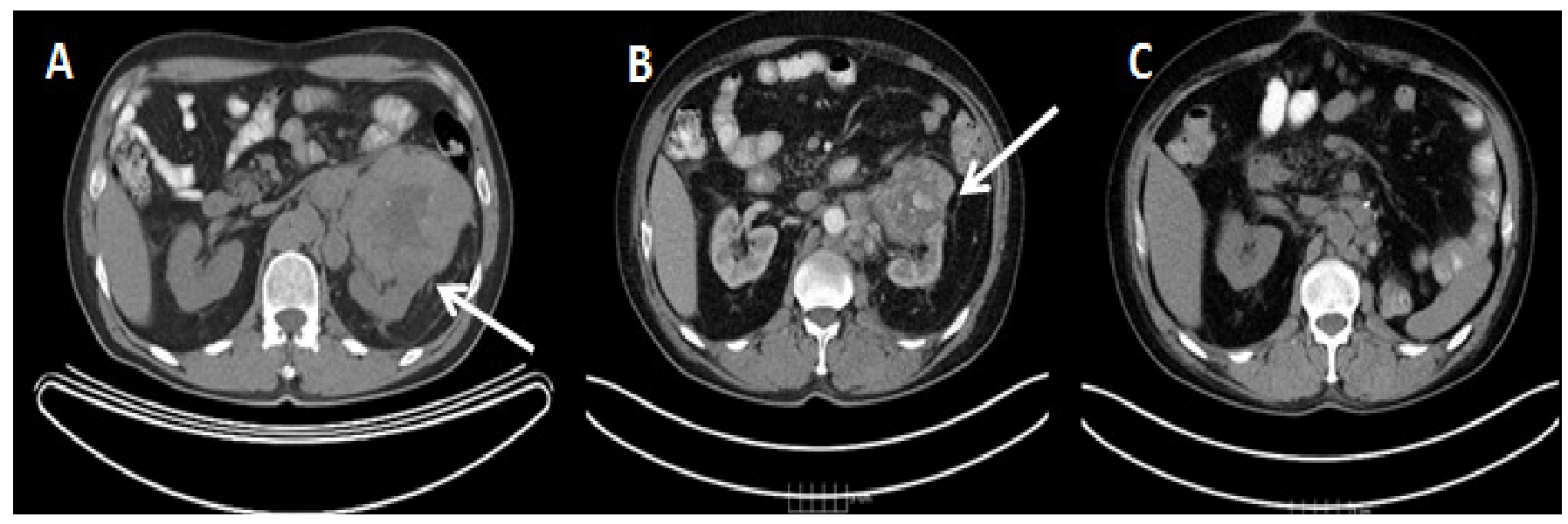

Fig. 2. A $11 \times 10 \mathrm{~cm}$ left upper pole renal mass with associated adenopathy. B Partial regression of tumor and adenopathy following three years of sequential targeted therapies. C Reimaging following cytoreductive nephrectomy.

ily history included a father alive at age 90 , a mother deceased at age 73 from lung cancer and 4 brothers and 3 sisters who were healthy. The patient was employed as a transit conductor for the municipal authority and was never married with no children. $\mathrm{He}$ denied smoking history and was a distance runner who had completed 49 marathons.

On examination, heart rate was 90 and blood pressure was $125 / 75 \mathrm{mmHg}$. He was $173 \mathrm{~cm}$ tall and weighed $77 \mathrm{~kg}$ with a body mass index of 25.8. He was comfortable and pleasant. There was no supraclavicular lymphadenopathy and the abdomen was soft with vague left upper quadrant fullness. There was no costovertebral angle tenderness. The testes were symmetric without masses and there was a visible left varicocele. The right femur incision was healing well with no lower extremity edema. Laboratory val-

Cytoreductive Nephrectomy after Targeted Therapy ues included hemoglobin $14.9 \mathrm{~g} / \mathrm{dl}$, hematocrit $45.1 \%$, platelets $464 \times 10^{9} / \mathrm{l}$, blood urea nitrogen $21 \mathrm{mg} / \mathrm{dl}$ and creatinine $1.18 \mathrm{mg} /$ dl. Calcium was elevated to $11.8 \mathrm{mg} / \mathrm{dl}$ and alkaline phosphatase level was $586 \mathrm{u} / 1$. Due to multifocal, metastatic diseases including central nervous system involvement, the patient was excluded from cytoreductive nephrectomy and referred to medical oncology for systemic therapy. He was also referred for neurosurgical evaluation and continued care by the orthopedic service.

In January of 2012 the patient began systemic treatment with Sunitinib. He received 3,000 cGy of palliative radiation to the right thigh and targeted stereotactic radiosurgery (SRS) of the brain lesion. He was offered standard whole brain radiation therapy to prevent future lesions but declined due to concerns about side effects. Restaging CT in March showed new pulmonary nodules 
Table 1.

\begin{tabular}{|c|c|c|c|}
\hline Treatment timeline & Adjunctive therapy & Central nervous system therapy & Systemic therapy \\
\hline November 2011 & pathologic right femur fracture with IM rod placement & & \\
\hline December 2011 & 3,000 cGy $\mathrm{R}$ femur radiation & stereotactic radiosurgery & \\
\hline April 2012 & & stereotactic radiosurgery & everolimus \\
\hline June 2012 & & & axitinib \\
\hline December 2012 & & stereotactic radiosurgery & \\
\hline September 2013 & & stereotactic radiosurgery & \\
\hline October 2013 & & & pazopinib \\
\hline November 2013 & & stereotactic radiosurgery & \\
\hline December 2013 & embolization of right femur lesion & & \\
\hline January 2014 & & stereotactic radiosurgery & \\
\hline
\end{tabular}

(fig. 1C) and pulmonary emboli and a right lower extremity deep venous thrombosis was diagnosed. Repeat brain imaging showed a new $5 \mathrm{~mm}$ right occipital lesion. In April, the patient began second-line therapy with Everolimus and another SRS procedure to the brain. In June, progressive lung metastases were noted and third-line Axitinib was started. Additional new brain lesions were noted and the patient underwent SRS procedures in December 2012 and March 2013. A partial response in extra central nervous system (CNS) disease from Axitinib lasted for one year until CT in July showed further disease progression. Fourth-line Bevacizumab began in August 2013. An additional SRS procedure was performed in September. Repeat CT in October showed disease progression and the patient was started on fifth-line Pazopanib. The patient underwent SRS in November for a small brain lesion and bland interventional embolization of the right femur lesion in December. Additional SRS for small brain metastases were performed in January, March and April of 2014. A partial response in extra CNS disease following Pazopanib lasted for 7 months and he was started on sixth-line Temsirolimus in April. CT scan in June showed regression of tumor with continued disease control evident on imaging in October. He underwent SRS of 2 new brain lesions that month. Based on sustained response to therapy with shrinkage of tumor burden, the patient was reconsidered for cytoreductive nephrectomy (table 1).

The patient was re-evaluated by the urologic oncology service in November 2014, 3 years after initial presentation. He reported independence in activities of daily living and denied constitutional or neurologic symptoms. He walked with a cane. He had a pulse of 86 and blood pressure of 150/84 $\mathrm{mmHg}$. The abdomen was soft and non-tender. There was no palpable adenopathy and no lower extremity edema. The most recent CT was reviewed with significant regression of the primary tumor and regional adenopathy (fig.
2B). Given sustained response to therapy and good performance status, the patient was now deemed a candidate for cytoreductive nephrectomy and the mass appeared amenable to a laparoscopic approach.

Following preoperative embolization of the left renal artery and an accessory lower pole vessel, laparoscopic nephrectomy was performed. The mass was adherent at the superior-medial border (fig. 3A) with significant fibrotic reaction around the hilum. The main artery and lower pole vessel were both identified and controlled with Endo GIA ${ }^{\mathrm{TM}}$ stapler and Weck Hem-o-lock ${ }^{\circledR}$ clips, respectively, and complete hemostasis was assured with bipolar cautery and 3-0 vicryl suture ligatures (fig. 3B). A small portion of the adrenal gland was resected with the kidney. Operative time was 3 hours and 55 minutes with $600 \mathrm{ml}$ of estimated blood loss. The patient remained hemodynamically stable and did not require blood products.

On pathologic examination the specimen measured $22.5 \times$ $11.5 \times 7.8 \mathrm{~cm}$ and weighed $940 \mathrm{~g}$. Cut section revealed a poorly circumscribed $7.0 \times 6.5 \mathrm{~cm}$ mass in the mid-kidney. The cut surface was tan-yellow with a nodular appearance with focal hemorrhage. Tumor was bulging the capsule into the perinephric fat. There was no renal vein invasion. The identified portion of adrenal gland was not involved with tumor. On histological examination, the tissue was consistent with Fuhrman grade 3 clear cell renal cell carcinoma with extensive infarct (fig. 4). There was embolization material noted in blood vessels.

The post-operative course was uneventful and the patient was discharged home on post-operative day one. Temsirolimus was resumed one week after surgery and the patient reported returning to his normal activities at the two week follow-up visit. The abdomen was soft with healing trocar and retrieval sites. An inferior vena cava filter was in place without lower extremity edema. 


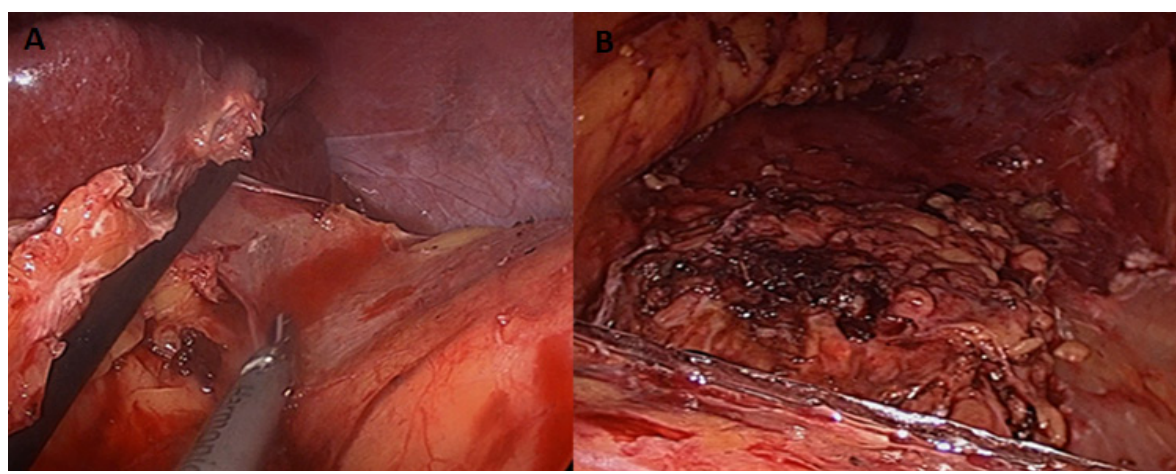

Fig. 3. A Notable adherence at the superior-medial border of the kidney. B The tumor is noted within a bag in the foreground with hemostasis of the renal fossa.

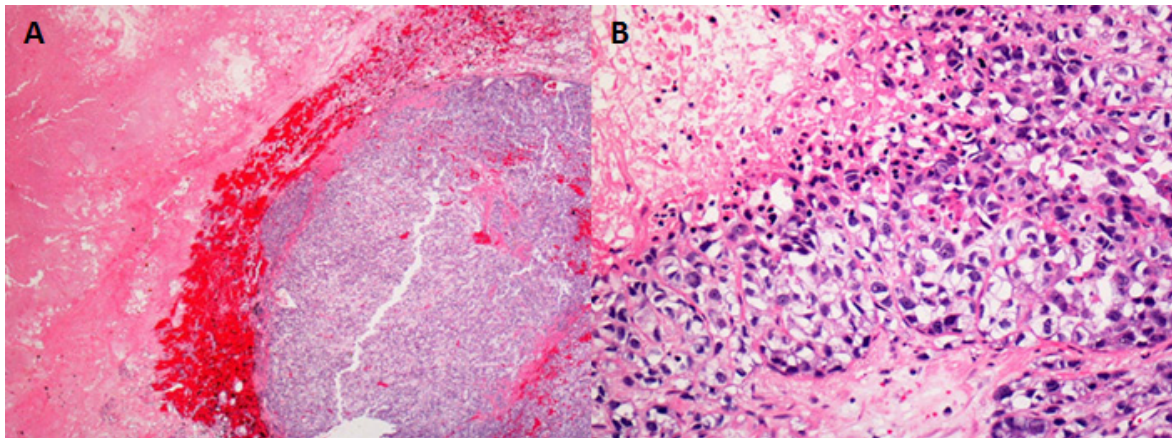

Fig. 4. Hematoxylin and eosin stain. A 40× magnification. B 200× magnification is consistent with Fuhrman nuclear grade 3 clear cell renal cell carcinoma with extensive necrosis.

Pathology results were reviewed and continued medical oncology management was advised. The patient was seen by medical oncology in March 2015 with no clinical complaints. He reported a good appetite and denied neurologic symptoms. ECOG performance status was 1 .

On physical examination, pulse was $80 / \mathrm{min}$ and blood pressure was $133 / 74 \mathrm{mmHg}$. His weight was $82 \mathrm{~kg}$ with a body mass index of 27.7. There was a pronounced rash on the face and chest. His abdomen was soft and non-tender with well-healed surgical port sites. The right hip incision was well healed and the right thigh was non-tender. There were no focal neurologic deficits. Hemoglobin was $9.5 \mathrm{~g} / \mathrm{dl}$, creatinine was $1.3 \mathrm{mg} / \mathrm{dl}$, albumin was $3.3 \mathrm{~g} / \mathrm{dl}$ and alkaline phosphatase was $105 \mathrm{u} / \mathrm{l}$. Recent magnetic resonance imaging of the thigh and $\mathrm{CT}$ of the chest, abdomen and pelvis showed stable disease (fig. 2C). Overall disease burden was well controlled and the patient was continued on Temsiroliumus. Pruritis was managed with diphenhydramine and his rash was not bothersome. The inferior vena cava filter remained in place without lower extremity edema. Denosumab and calcium were continued in light of bone metastasis.

Cytoreductive Nephrectomy after Targeted Therapy

\section{Discussion}

We present a 55-year-old male diagnosed with metastatic renal cell carcinoma following a pathologic femur fracture. Despite good performance status, multifocal metastases and poor-prognostic features portended a grim prognosis with predicted overall survival of less than nine months [1]. He was excluded from cytoreductive nephrectomy based on brain metastasis and interleukin-2 was not pursued as the primary tumor was to be left in situ. The higher disease control rate and better side effect profile of targeted therapy made it the preferable first-line approach.

Inhibition of the vascular-endothelial growth factor (VEGF) pathway can be accomplished by either blocking the binding of VEGF to its receptor or by inhibiting intracellular tyrosine kinase domain of the VEGF recep- 
tor using small molecules such as Sunitinib have become the primary therapies for patients with advanced renal cell carcinoma [22]. At his initial presentation, available trials showed a benefit of targeted therapy compared to interferon but limited comparisons between agents and no data on optimal sequencing. The standard approach in treatment naïve patients was to start with either Sunitinib or Pazopinib. Less commonly used agents were Bevacizumab and interferon inpatients with good to intermediate prognosis disease. Temsirolimus was the treatment of choice in poor prognostic or non-clear cell histology [2, $3]$. In retrospect, Temsirolimus may have been a better first line agent in this poor prognostic patient, but recent data showed first line Sunitinib followed by Everolimus to be preferable to the reverse order, even in poor prognostic patients [4]. When the patient progressed in April 2012, Everolimus and Axitinib were both approved as second-line therapy. The common practice was to switch drug classes if there had not been a good response to firstline tyrosine kinase inhibitor (TKI) thus he was started on second-line Everolimus. Since that time, there is evidence that TKI followed by TKI may be superior to TKI followed by mammalian target of Rapamycin inhibitor [5]. When second-line treatment failed, there was limited evidence to support any particular agent for third-line therapy. In this strong-willed patient with good performance status, we believed all available treatment should be offered and in fact hospice was briefly discussed before the initiation of Temsirolimus but he refused.

Rather than defining a uniform algorithm for all patients, an individualized approach will likely guide systemic therapy in the future. Advancements in genome sequencing and identifying relevant mutations in specific tumors will identify those most likely to benefit from particular agents $[6,7]$. Furthermore, promising results with newer immunotherapies such as the anti-PD-1 antibody Nivolumab offer an emerging approach to therapy with significant growth in this class likely in the future [8]. We plan to offer Nivolumab if this patient progresses on Temsirolimus. The role of cytoreductive nephrectomy in the setting of metastatic disease is evolving.

In the era of immunotherapy, upfront cytoreductive nephrectomy conferred a 6-month survival advantage [9]. Despite the controversy regarding candidacy cytoreduction, classic qualifying criteria include clear cell histology, no CNS, bone or liver metastasis, good performance status and greater than $75 \%$ tumor debulking [10]. Preliminary retrospective studies support a benefit of surgery combined with targeted therapy and the prospective CARMENA trial will more clearly define the impact [11,
12]. Recent studies suggest that overall tumor burden or specific sites of metastatic disease are not necessarily exclusion criteria for cytoreduction $[1,13]$. The appropriate timing of cytoreductive nephrectomy also remains under investigation. Early nephrectomy is beneficial if hemorrhage limits the delivery of systemic therapy and for symptom palliation. In addition, early surgery avoids operating in the poor healing environment associated with targeted therapy [14]. But there are several persuasive arguments in favor of delaying nephrectomy. A trial of neoadjuvant systemic therapy avoids the associated risks of surgery in progressors who derive little benefit from debulking. As noted in this case, a large primary tumor may be downsized with a reduction in hilar adenopathy facilitating a laparoscopic approach. The patient thus benefited from a decreased wound burden, earlier convalescence and short interval off of systemic therapy. Due to the recent overall improvement in robotic/laparoscopic surgery in urology over the past two decades, the historic morbidity related to cytoreductive reported in the literature now seems to be inconsistent and outdated. The decision to not perform a retroperitoneal lymph node dissection is this patient was mostly due to the lack of information and therapeutic benefit it would have added to this patient's overall cancer specific survival with additional unnecessary morbidity.

From a diagnostic perspective, the primary tumor may offer radiographic insight into the response to systemic therapy [15]. While EORTC 30073 will provide prospective evidence regarding cytoreductive nephrectomy after 3 cycles of Sunitinib, there is scant literature on nephrectomy after several years of targeted therapy [16]. Though our patient was excluded from nephrectomy at initial presentation, there was multi-disciplinary consensus that extended survival, continued response to therapy and good performance status ultimately made him a candidate for surgery. There was preoperative concern about fibrosis and adenopathy around the hilum thus preoperative angiographic embolization was performed. In 279 cytoreductive nephrectomies in the United Kingdom in 2012, 111 were performed laparoscopically with 16 requiring open conversion. Laparoscopic cases had a lower rate of blood transfusion. Of note, 40 patients received preoperative TKIs with no impact on complications [17]. The presence of brain metastasis also deserves rethinking as targeted therapies are extending survival and perhaps even decreasing the incidence [18].

Although whole brain radiotherapy (WBRT) remains a standard treatment and is thought to prevent the development of lesions, technological advances in SRS and 
concerns over adverse neurocognitive effects of WBRT have impacted treatment decisions. Recent guidelines reflect the complexity of the choices $[19,20]$. In general, the use of SRS alone to avoid WBRT has been used in patients with up to 4 metastatic lesions; however, recent data suggests improved survival in up to 10 lesions [21]. Given the minimal morbidity of SRS, many practitioners and patients consider repetitive procedures an acceptable trade-off to avoid WBRT-associated side effects. In this case, WBRT was offered but declined by the patient. After 10 procedures, he is free of radiographic disease with no neurologic deficits.

This case report describes a successful case who underwent multi-modal therapy including the sequential targeted therapy and repetitive stereotactic radiation therapies followed by deferred cytoreductive nephrectomy. Our patient presented with diffuse metastatic disease with a poor prognosis. This case report describes that we should not give up the treatment of the patients with multiple metastastic renal cell cancer. We used various targeted agents sequentially and we should treat brain metastases by repetitive stereotactic radiation therapies. Systemic therapy was changed swiftly in the face of progression while brain lesions were focally eradicated with preservation of neurologic function. If these treatments are effective, occasionally the patient can undergo deferred cytoreductive nephrectomy. Cytoreductive nephrectomy was delayed until meaningful response was demonstrated and performed laparoscopically with early recovery and minimal time off systemic therapy. As we further optimize systemic therapy and adjunctive treatments to specific sites of disease, we will continue to extend the quality and quantity of life of patients with renal cell carcinoma.

\section{References}

1 Heng DY, Xie W, Regan MM, Warren MA, Golshayan AR, Sahi C, Eigl BJ, Ruether JD, Cheng T, North S, Venner P, Knox JJ, Chi $\mathrm{KN}$, Kollmannsberger C, McDermott DF, Oh WK, Atkins MB, Bukowski RM, Rini BI, Choueiri TK: Prognostic factors for overall survival in patients with metastatic renal cell carcinoma treated with vascular endothelial growth factor-targeted agents: results from a large, multicenter study. J Clin Oncol 2009; 27:5794-5799.

2 Motzer RJ, Hutson TE, Tomczak P, Michaelson MD, Bukowski RM, Rixe O, Oudard S, Negrier S, Szczylik C, Kim ST, Chen I, Bycott PW, Baum CM, Figlin RA: Overall survival and up- dated results for sunitinib compared with interferon alfa in patients with metastatic renal cell carcinoma. J Clin Oncol 2009;27:3584-3590.

3 Hudes G, Carducci M, Tomczak P, Dutcher J, Figlin R, Kapoor A, Staroslawska E, Sosman J, McDermott D, Bodrogi I, Kovacevic Z, Lesovoy V, Schmidt-Wolf IG, Barbarash O, Gokmen E, O'Toole T, Lustgarten S, Moore L, Motzer RJ: Temsirolimus, interferon alfa, or both for advanced renal-cell carcinoma. $\mathrm{N}$ Engl J Med 2007;356:2271-2281.
4 Motzer RJ, Barrios CH, Kim TM, Falcon S, Cosgriff T, Harker WG, Srimuninnimit V, Pittman K, Sabbatini R, Rha SY, Flaig TW, Page R, Bavbek S, Beck JT, Patel P, Cheung FY, Yadav S, Schiff EM, Wang X, Niolat J, Sellami D, Anak O, Knox J: Phase II randomized trial comparing sequential first-line everolimus and second-line sunitinib versus firstline sunitinib and second-line everolimus in patients with metastatic renal cell carcinoma. J Clin Oncol 2014;32:2765-2772.

5 Hutson TE, Escudier B, Esteban E, Bjarnason GA, Lim HY, Pittman KB, Senico P, Niethammer A, Lu DR, Hariharan S, Motzer RJ: Randomized phase III trial of temsirolimus versus sorafenib as second-line therapy after sunitinib in patients with metastatic renal cell carcinoma. J Clin Oncol 2013;32:760-767.

6 Iyer G, Hanrahan AJ, Milowsky MI, Al-Ahmadie H, Scott SN, Janakiraman M, Pirun M, Sander C, Socci ND, Ostrovnaya I, Viale A, Heguy A, Peng L, Chan TA, Bochner B, Bajorin DF, Berger MF, Taylor BS, Solit DB: Genome sequencing identifies a basis for everolimus sensitivity. Science 2012;338:221.
7 Voss MH, Hakimi AA, Pham CG, Brannon AR, Chen YB, Cunha LF, Akin O, Liu H, Takeda S, Scott SN, Socci ND, Viale A, Schultz N, Sander C, Reuter VE, Russo P, Cheng EH, Motzer RJ, Berger MF, Hsieh JJ: Tumor genetic analyses of patients with metastatic renal cell carcinoma and extended benefit from mTOR inhibitor therapy. Clin Cancer Res 2014;20:1955-1964.

8 McDermott DF, Drake CG, Sznol M, Choueiri TK, Powderly JD, Smith DC, Brahmer JR, Carvajal RD, Hammers HJ, Puzanov I, Hodi FS, Kluger HM, Topalian SL, Pardoll DM, Wigginton JM, Kollia GD, Gupta A, McDonald D, Sankar V, Sosman JA, Atkins MB: Survival, durable response, and long-term safety in patients with previously treated advanced renal cell carcinoma receiving nivolumab. J Clin Oncol 2015;33:20132020.

9 Flanigan RC, Salmon SE, Blumenstein BA, Bearman SI, Roy V, McGrath PC, Caton JR Jr, Munshi N, Crawford ED: Nephrectomy followed by interferon alfa- $2 b$ compared with interferon alfa- $2 b$ alone for metastatic renalcell cancer. N Engl J Med 2001;345:16551659. 
10 Fallick ML, McDermott DF, Larock DJ, Long JP, Atkins MB: Nephrectomy before interleukin-2 therapy for patients with metastatic renal cell carcinoma. J Urol 1997;158:16911695.

11 Choueiri TK, Xie W, Kollmannsberger C, North S, Knox JJ, Lampard JG, McDermott DF, Rini BI, Heng DY: The impact of cytoreductive nephrectomy on survival of patients with metastatic renal cell carcinoma receiving vascular endothelial growth factor targeted therapy. J Urol 2011;185:60-66.

12 "Clinical trial to assess the importance of nephrectomy (CARMENA)," US National Institutes of Health, http://clinicaltrials.gov/ ct2/show/NCT00930033.

13 Heng DY, Wells JC, Rini BI, Beuselinck B, Lee JL, Knox JJ, Bjarnason GA, Pal SK, Kollmannsberger CK, Yuasa T, Srinivas S, Donskov F, Bamias A, Wood LA, Ernst DS, Agarwal N, Vaishampayan UN, Rha SY, Kim JJ, Choueiri TK: Cytoreductive nephrectomy in patients with synchronous metastases from renal cell carcinoma: results from the 11 international metastatic renal cell carcinoma database consortium. Eur Urol 2014;66:704710 .
14 Thomas AA, Rini BI, Stephenson AJ, Garcia JA, Fergany A, Krishnamurthi V, Novick AC, Gill IS, Klein EA, Zhou M, Campbell SC: Surgical resection of renal cell carcinoma after targeted therapy. J Urol 2009;182:881886.

15 Powles T, Blank C, Chowdhury S, Horenblas S, Peters J, Shamash J, Sarwar N, Boleti E, Sahdev A, O'Brien T, Berney D, Beltran L, Nathan P, Haanen J, Bex A: The outcome of patients treated with sunitinib prior to planned nephrectomy in metastatic clear cell renal cancer. Eur Urol 2011;60:448-454.

16 EORTC 30073/SURTIME trial - NCT01099 423.

17 Jackson BL, Fowler S, Williams ST: Perioperative outcomes of cytoreductive nephrectomy in the UK in 2012. BJU Int 2015;116: 905-910.

18 Verma J, Jonasch E, Allen P, Tannir N, Mahajan A: Impact of tyrosine kinase inhibitors on the incidence of brain metastasis in metastatic renal cell carcinoma. Cancer 2011;117: 4958-4965.
19 Tsao MN, Rades D, Wirth A, Lo SS, Danielson BL, Gaspar LE, Sperduto PW, Vogelbaum MA, Radawski JD, Wang JZ, Gillin MT, Mohideen N, Hahn CA, Chang EL: Radiotherapeutic and surgical management for newly diagnosed brain metastasis(es): An American Society for Radiation Oncology evidence-based guideline. Pract Radiat Oncol 2012;2:210-225.

20 NCCN clinical practice guidelines https:// www.nccn.org/store/login/login.aspx?ReturnURL=http://www.ncen.org/professionals/ physician_gls/pdf/cns.pdf.

21 Yamamoto M, Serizawa T, Shuto T, Akabane A, Higuchi Y, Kawagishi J, Yamanaka K, Sato Y, Jokura H, Yomo S, Nagano O, Kenai H, Moriki A, Suzuki S, Kida Y, Iwai Y, Hayashi M, Onishi H, Gondo M, Sato M, Akimitsu T, Kubo K, Kikuchi Y, Shibasaki T, Goto T, Takanashi M, Mori Y, Takakura K, Saeki N, Kunieda E, Aoyama H, Momoshima S, Tsuchiya $\mathrm{K}$ : Stereotactic radiosurgery for patients with multiple brain metastases (JLGK0901): a multi-institutional prospective observational study. Lancet Oncol 2014;15:387-395.

22 Battelli C, Cho DC: mTOR inhibitors in renal cell carcinoma. Therapy 2011;8:359-367. 